\title{
SUCCESSFUL LOCAL EXCISION AND LONG-TERM SURVIVAL FOR INVASIVE PULMONARY ASPERGILLOSIS DURING NEUTROPENIA AFTER BONE MARROW TRANSPLANTATION
}

\author{
James M. Habicht, MD, ${ }^{\mathrm{a}}$ Jakob Passweg, MD, MS, ${ }^{\mathrm{b}}$ Thomas Kuhne, MD,${ }^{\mathrm{c}}$ Kurt Leibundgut, MD, ${ }^{\mathrm{d}}$ and \\ Hans-Reinhard Zerkowski, Prof, ${ }^{\mathrm{a}}$ Basel and Bern, Switzerland
}

Invasive pulmonary aspergillosis in patients with neutropenia carries a high mortality. Early resection of localized invasive pulmonary aspergillosis is being advocated by an increasing number of authors, ${ }^{1-5}$ but definite proof of efficacy is still missing. Controversy also exists as to whether the lesions should be eradicated locally (enucleated) or radically (wedge resection, lobectomy, or even pneumonectomy). ${ }^{6}$ This question is particularly important with hilar lesions.

This article reports a case of successful enucleation with topical application of amphotericin B in a young patient who otherwise would have required pneumonectomy.

Clinical summary. A 15-year-old girl with acute myeloid leukemia FAB M7 underwent induction and consolidation treatment on a pediatric oncology group protocol and achieved first complete remission. The leukemia relapsed 9 months later, presenting with complex cytogenetic abnormalities. The girl underwent reinduction treatment with 2chlorodeoxyadenosine and idarubicin, but residual blasts persisted in the marrow. She then underwent allogeneic peripheral stem cell transplantation (PSCT) in second partial remission with her HLA-identical sister as the donor. Conditioning was performed with cyclophosphamide $2 \times 60$ $\mathrm{mg} / \mathrm{kg}$, VP-16 $30 \mathrm{mg} / \mathrm{kg}$, and 12-Gy total body irradiation in 6 fractions. Thereafter, $5.92 \times 10^{6}$ unmanipulated CD34+ cells per kilogram were transplanted. On day 2 before PSCT a conventional chest $\mathrm{x}$-ray film showed no abnormalities. On day 1 after PSCT, her temperature rose to $40.4^{\circ} \mathrm{C}$ and the concentration of C-reactive protein increased to $206 \mathrm{mg} / \mathrm{L}$. She had no respiratory symptoms or chest pain. The patient had had aplasia for 12 days. Antifungal therapy with amphotericin B $1 \mathrm{mg} / \mathrm{kg}$ per day was initiated. A computed tomographic scan of the chest showed two perihilar lesions in the upper and lower lobes of the left lung, highly suggestive of invasive aspergillosis (Fig 1). To avoid left pneumonectomy both lesions were enucleated on day 3 after PSCT. To prevent bleeding complications during the operation, single donor

From the Divisions of Cardiothoracic Surgery, ${ }^{a}$ Hematology, ${ }^{\mathrm{b}}$ and Pediatric Oncology, ${ }^{\mathrm{c}}$ University Hospital, Basel, Switzerland, and the Division of Pediatric Oncology, Inselspital University Hospital, Bern, Switzerland. ${ }^{\mathrm{d}}$

Received for publication Jan 6, 2000; accepted for publication Jan 12, 2000.

Address for reprints: James M. Habicht, MD, Division of Cardiothoracic Surgery, University Hospital Basel, CH-4031 Basel, Switzerland (E-mail: jhabicht@uhbs.ch).

J Thorac Cardiovasc Surg 2000;119:1286-7

Copyright $\odot 2000$ by The American Association for Thoracic Surgery 0022-5223/2000 $\$ 12.00+0 \quad \mathbf{1 2 / 5 4 / 1 0 5 7 4 9}$

doi: $10.1067 / \mathrm{mtc} .2000 .105749$ platelets were transfused. At the start of the operation, the platelet count was $38 \times 10^{9} / \mathrm{L}$. The parietal pleura adjacent to the descending thoracic aorta was already infiltrated by Aspergillus and also was resected. The cavities resulting from enucleation were partially filled with collagen sponge impregnated with amphotericin B and then fixed with fibrin glue. The lung was resutured over the sponge. Histologic studies and cultures confirmed angioinvasive Aspergillus fumigatus. The postoperative course was uneventful. Antibiotics and amphotericin B, as well as granulocyte colony stimulating factor, were continued. Granulocytes were transfused on days 4 to 8 and the neutrophil count rose to $1.48 \times 10^{9} / \mathrm{L}$. Thereafter, the neutrophil counts continued to rise with stable engraftment. There was no postoperative bleeding and air leak was minimal ( 2 days). The last drain was removed on day 8. Respiration deteriorated on day 9 with patchy confluent infiltrates in both lower lobes and some ground-glass pattern necessitating diuretics and positive-pressure mask respiration, but not intubation. The patient recovered within 3 days. The reasons for this deterioration did not become entirely clear. Transfusion-associated lung injury, post-transplantation interstitial pneumonitis, progressive fungal infection, and fluid overload were considered as causes. There was no evidence of graft-versus-host disease. The patient remained afebrile and was discharged on day 26 after PSCT on a program of intravenous amphotericin B. Liposomal amphotericin B was continued up to day 105. Now, 12 months after PSCT, there is no evidence of leukemia or recurrent fungal infection.

Comment. This case demonstrates successful combined surgical and medical treatment of histologically proven invasive pulmonary aspergillosis immediately after bone marrow transplantation for acute myeloid leukemia. Surgery was performed during the aplastic phase due to conditioning therapy. Main pillars of treatment in this difficult situation were early surgery, systemic and local administration of amphotericin B, and, possibly, granulocyte transfusions during the initial postoperative phase. Important points to consider are whether the patient benefited from the operation, as engraftment occurred soon thereafter, and whether enucleation was preferable to other types of intervention.

The speed of engraftment and thus the duration of aplasia could not be predicted at the time of decision-making. The lesions grew rapidly, a known phenomenon which calls for therapeutic intervention. The lesions were adjacent to the hilum of the lobes. Central localization is a known risk factor for massive hemoptysis, ${ }^{7}$ which unfortunately seems to occur quite often during granulocyte recovery ${ }^{1,8}$ or later, after development of cavitary abscess. ${ }^{9}$ Waiting for leukocyte recovery therefore did not seem to be a valid option and, like others, ${ }^{10}$ 

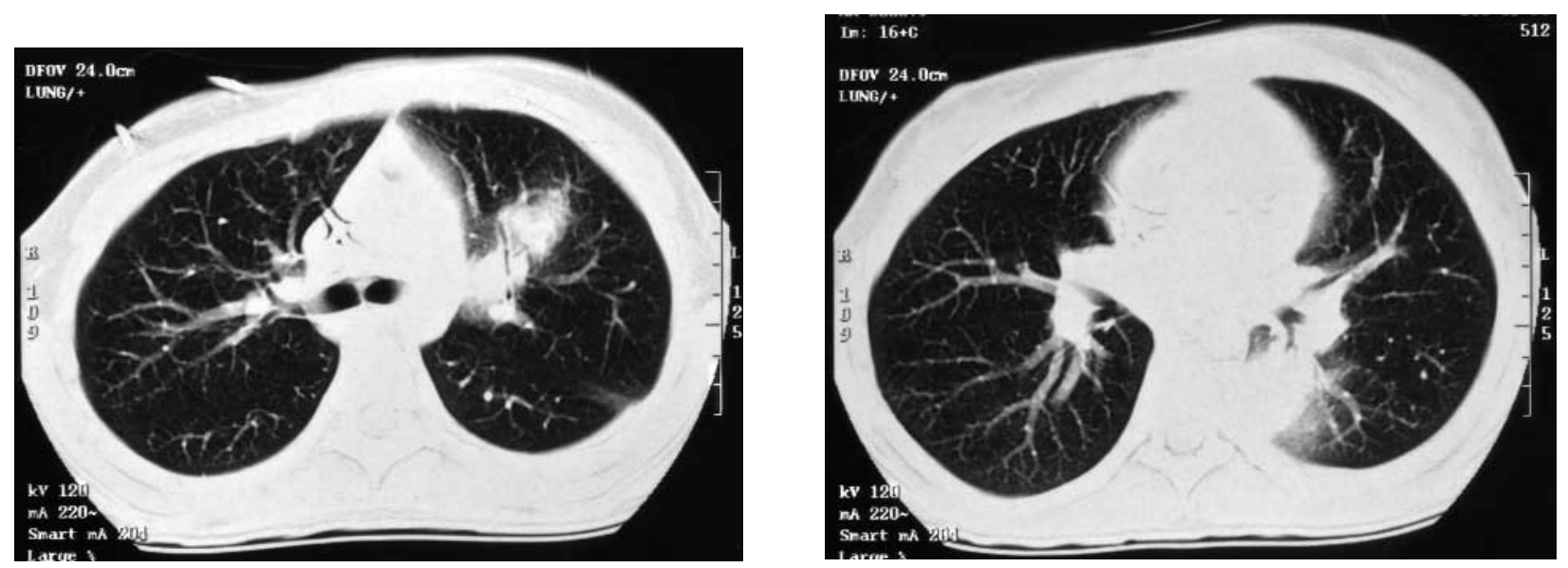

Fig 1. Early localized invasive pulmonary aspergillosis in a 15 -year old patient with neutropenic leukemia occurring just after bone marrow transplantation. Notice the central location in the hilum of the upper and lower left lobes. Enucleation with application of a collagen sponge impregnated with amphotericin B was successful, and the patient is free of fungal infection 12 months after the operation.

we performed the resection early, 1 day after a computed tomographic scan confirmed the clinical suspicion. Pneumonectomy for invasive pulmonary aspergillosis is only rarely indicated and has been performed in less than $4 \%$ of surgical cases published since $1990 .{ }^{11}$ Besides creating a substantial loss of pulmonary function, pneumonectomy also leaves the patient with a large cavity that may remain permanently contaminated in case of fungal dissemination. Also, large resections may decrease options for further chemotherapy because of subsequent damage to pulmonary vessels. As favorable outcomes have been reported occasionally with incomplete resections ${ }^{11}$ and local excision of lung tissue infarcted by invasive aspergillosis, ${ }^{6}$ enucleation with topical administration of amphotericin B was performed. There are now 3 cases of proven invasive pulmonary aspergillosis (2 published and 1 unpublished) in our own series in which this procedure was done, and fungal infection was cleared in all 3 cases ( 1 patient died 1 1/2 years later of a leukemic relapse).

However, we perform enucleations only in exceptional cases. Early wedge resection and lobectomy continue to be the standard procedures whenever feasible without severe loss of lung function.

\section{REFERENCES}

1. Wong K, Waters CM, Walesby RK. Surgical management of invasive pulmonary aspergillosis in immunocompromised patients. Eur J Cardiothoracic Surg 1992;72:3223-6.

2. Robinson LA, Reed EC, Galbraith TA, Alonso A, Moulton AL, Fleming WH. Pulmonary resection for invasive Aspergillus infections in immunocompromised patients. J Thorac Cardiovasc Surg 1995;109:1182-97.
3. Reichenberger F, Habicht JM, Kaim P, Dalquen P, Bernet F, Schlapfer $\mathrm{R}$, et al. Lung resection for invasive pulmonary aspergillosis in neutropenic patients with hematologic diseases. Am J Respir Crit Care 1998;158:885-90.

4. Baron O, Guillaumé B, Moreau P, Germaud P, Despins P, De Lajartre AY, et al. Aggressive surgical management in localized pulmonary mycotic and nonmycotic infections for neutropenic patients with acute leukemia: report of eighteen cases. J Thorac Cardiovasc Surg 1998;115:63-9.

5. Salerno CT, Ouyang DW, Pederson TS, Larson DM, Shake JP, Johnson EM, et al. Surgical therapy for pulmonary aspergillosis in immunocompromised patients. Ann Thorac Surg 1998;65:1415-9.

6. Kim J. Discussion of Baron et al. ${ }^{4}$

7. Caillot D, Casasnovas O, Bernard A, Couaillier JF, Durand C, Cuisinier B, et al. Improved management of invasive pulmonary aspergillosis in neutropenic patients using early thoracic computed tomographic scan and surgery. J Clin Oncol 1997;15:139-47.

8. Albelda SM, Talbot GM, Gerson SL, Miller WT, Cassileth PA. Pulmonary cavitation and massive hemoptysis in invasive pulmonary aspergillosis: influence of bone marrow recovery in patients with acute leukemia. Am Rev Respir Dis 1985;131:11520.

9. Moreau P, Zahar JR, Milpied N, Baron O, Mahe B, Wu D, et al. Localized invasive pulmonary aspergillosis in patients with neutropenia: effectiveness of surgical resection. Cancer 1993;72:3223-6.

10. Pomerantz M. Discussion of Baron et al. ${ }^{4}$

11. Habicht JM, Reichenberger F, Gratwohl A, Zerkowski H-R, Tamm M. Surgical aspects of resection for suspected invasive pulmonary fungal infection in neutropenic patients. Ann Thorac Surg 1999;68:321-5. 